\title{
Gobernanza política en Latinoamérica en tiempos del coviD-19
}

\section{Politic governance in Latin America in times of CovID-19}

\author{
Carla Torcoletti ${ }^{1}$
}

\begin{abstract}
Resumen
Este trabajo aporta una mirada sobre Latinoamérica, y presta especial atención al concepto de gobernanza, especialmente en el contexto de la pandemia de covid-19. El virus ha traído innumerables efectos negativos en la región que deben tratar de mitigarse a partir del acuerdo y la toma de decisiones eficaces de los gobiernos. Antes de la pandemia, la región mostraba una complicada situación de gobernanza en muchos de sus países, por lo que la explosión del virus no hizo más que acentuarla.

En este trabajo, definiremos el concepto gobernan$z a$, para luego hablar de sus diferentes aspectos y ver cómo se traducen empíricamente en los Estados que conforman esta región. Abordaremos el indicador del juego de poder entre los actores y la calidad del sistema, y analizaremos cómo la pandemia ha venido a plantear - al menos - enormes interrogantes sobre los modos de los gobiernos para conducir y direccionar sus sociedades.
\end{abstract}

Palabras clave: gobernanza - Latinoamérica - covid-19 - perspectivas

\begin{abstract}
This paper provides an overview of Latin America, and pays particular attention to the concept of governance, especially in the context of the COVID-19 pandemic. The virus has brought countless negative effects to the region that should be mitigated through effective government agreement and decision-making. The region, prior to the pandemic, showed a complicated governance situation in many of its countries, and the explosion of the virus only accentuated that situation.

In this paper, we will define the concept of governance and then discuss its different aspects, and see how they empirically translate into the States of our region. We will address the indicator of the power game among the actors and the quality of the system, and how the pandemic has come to pose - at least - enormous questions about the ways in which governments conduct and direct their societies.
\end{abstract}

Keywords: governance - Latin America - covid-19 - perspectives

\section{Relaciones Internacionales/ ensayo científico}

Citar: Torcoletti, C. (2020). Gobernanza política en Latinoamérica en tiempos del COVID-19. Omnia. Derecho y sociedad, 3 (3), pp. 101-108.

\footnotetext{
1 Universidad Católica de Santiago del Estero. Licenciada en Ciencia Política Universidad Nacional de la Patagonia San Juan Bosco (UNPSJB); docente en la Licenciatura en Relaciones Internacionales en la Universidad Católica de Santiago del Estero-Departamento Académico San Salvador (UCSE-DASS); docente en el Instituto Superior de Seguridad Pública de Jujuy; coordinadora del área de Ciencia Política y del Observatorio de Políticas Públicas del Centro de Estudios en Ciencia Política y Relaciones Internacionales de la UCSE-DASS. Investigadora dentro de la UCSE-DASS. tcarla@gmail.com
} 


\section{INTRODUCCIÓN}

Para comenzar a adentrarnos en los adversos y complicados vaivenes de la variable gobernanza en los escenarios latinoamericanos en los tiempos del coviD-19, es imprescindible explicitar en primer lugar qué entendemos por "gobernanza".

En boca de diferentes autores, este concepto muestra diversos matices. Por ejemplo, Beltramin (2016) la define como "aquella capacidad que tienen las sociedades para proveer un sistema de gobierno que permita el desarrollo de los sistemas sociales y obviamente, de los individuos que forman parte de ellos" (p. 150). Si bien esta definición pone el acento en el concepto de desarrollo, particularmente interesante para este trabajo, deja fuera elementos que consideramos centrales para comprender el fenómeno, como ser el papel de las relaciones entre los actores sociales y políticos. A causa de ello, en este ensayo, recuperaremos la siguiente definición que incorpora perspectivas que la anterior deja de lado:

Gobernanza es la realización de relaciones políticas entre diversos actores involucrados en el proceso de decidir, ejecutar y evaluar decisiones sobre asuntos de interés público, proceso que puede ser caracterizado como un juego de poder, en el cual competencia y cooperación coexisten como reglas posibles; y que incluye instituciones tanto formales como informales. La forma e interacción entre los diversos actores refleja la calidad del sistema y afecta a cada uno de sus componentes; así como al sistema como totalidad. (Whittingham Munévar, 2010, p. 222)

Antes de desenredar la trama de esta última definición y mirar a través de ella al subcontinente americano, debemos señalar que este concepto se acuñó porque los Estados, luego de las crisis de posguerra (y este rasgo se profundiza medida que el tiempo pasa), se encuentran condicionados por numerosos factores internos y externos que les impiden el grado de libertad de acción que antes tenían. Con la globalización avanzando y transformándose en "glocalización" (Robertson, 2003) desde hace décadas, los Estados van perdiendo su soberanía en muchos aspectos: en lo económico, lo social y lo político, por nombrar solo algunos. En este marco, es útil el concepto de gobernanza, pues permite ver todas las caras del desarrollo de un Estado (o de su estancamiento o debilitamiento, si fuera el caso). Para analizar el tema que nos ocupa en el presente trabajo es preciso tener claro dicho concepto.

Como sabemos, la pandemia ha trastocado todos los ámbitos de la vida de los Estados y los individuos. Al decir de Sanahuja (2020), "la pandemia de la covid-19 tiene un alcance sistémico, ya que afecta a todas las dimensiones de la vida social, y se proyecta a escala global" (p. 28). Por esta razón, se hace necesaria la reflexión sobre el fenómeno, e intentaremos ver aquí los aspectos más importantes de este alcance sistémico de la emergencia sanitaria.

Los escenarios en los que nos sitúa la pandemia tienen matices muy variados según el contexto geográfico desde donde los miremos. Hay Estados latinoamericanos que, ante los efectos negativos del covid-19, se han encontrado mucho más preparados y organizados que otros. Sin embargo, a pesar de las diferencias, podemos coincidir en que en América Latina el aspecto sanitario tiene un cuadro mucho más complejo que en los países europeos, donde el virus hizo estragos (como Italia y España). Antes de la llegada de la pandemia, nuestros países tenían una complicada situación sanitaria y destinaban muchos menos recursos a salud pública que los países europeos. 
Para ilustrar lo anterior, veamos algunos datos de la región: Brasil, que es el que tiene uno de los mejores sistemas de salud de Latinoamérica, invierte en él menos de la mitad de lo que invierte España en el suyo (Arturo Wallace, 2020). Además del gasto, otro problema es la distribución de los servicios de salud: es muy desigual e inequitativa. De hecho, la Organización Panamericana de la Salud (OPS) calcula que un $30 \%$ de la población latinoamericana no tiene acceso a la atención sanitaria por razones económicas (OPS, 2019). Esta pandemia tendrá devastadoras consecuencias sobre uno de los bienes públicos más importantes que debe resguardar el Estado: la salud. Pero, por supuesto, las consecuencias no se darán solo en ese campo.

\section{ESCENARIO ECONÓMICO Y SOCIAL}

Pasemos ahora al aspecto económico. Luego de la crisis, quedará (ya lo estamos viendo) un quiebre sin precedentes, tanto del lado de la oferta como de la demanda: la interrupción de las cadenas de producción, las alarmantes disminuciones de ganancias, la pérdida de capacidad de compra de los consumidores, el aumento del desempleo, entre otros. No solo para los ciudadanos y las empresas hay oscuros horizontes en el futuro, sino también para los Estados que, entre otras cosas, ven que la actividad económica de sus principales socios comerciales ha caído estrepitosamente (es el caso, por ejemplo, de China). Entonces, nuestros países se ven obligados a endeudarse irremediablemente para intentar sortear, en el presente, los apremiantes compromisos que supone sostener la economía y, a la vez, resguardar la salud de la mayor cantidad de ciudadanos posible. A futuro, esto los llevará a verse imposibilitados de cumplir con las obligaciones de la deuda y, por supuesto, podría producir que sus tasas de crecimiento sean bajísimas, cuando no negativas.

Dedicaremos ahora unas líneas a la cuestión social. La retracción ( $y$, en muchos casos, paralización) de la actividad económica está llevando al aumento del subempleo y el desempleo, fenómeno que afecta sobre todo a los grupos más vulnerables, como los del sector informal. La Organización Internacional del Trabajo (2020) estima que es probable que las familias más pobres envíen a sus hijos a trabajar, lo cual aumentará la cantidad ya elevada de trabajo infantil registrada antes de la pandemia. Según estimaciones de la OIT, 7,3 \% de los niños de 5 a 17 años (unos 10,5 millones en la región) trabajan.

Todo lo dicho se traducirá en el aumento de los índices de pobreza y de pobreza extrema. La crisis tendrá impactos más profundos entre los grupos más vulnerables y desprotegidos como son los adultos mayores, las personas con enfermedades crónicas, los trabajadores informales y/o migrantes, los jóvenes desempleados, las personas subempleadas y las mujeres. Esto, inevitablemente, conllevará una profundización de la desigualdad.

Otras expresiones en esta línea son el agravamiento del racismo y la xenofobia en la región. Los gobiernos, tanto a nivel nacional como local, están restringiendo el tránsito de personas a través de las fronteras, para intentar contener los contagios. Este proceso tiene como contracara que muchos ciudadanos señalan como vehículo del contagio a determinados grupos sociales relacionados con etnias o nacionalidades específicas. Por ejemplo, en la frontera argentino-boliviana, el cruce ilegal de bolivianos hacia la Argentina profundiza los problemas preexistentes relacionados con el uso de servicios estatales argentinos por parte de personas extranjeras, servicios y recursos que hoy se muestran como insuficientes para los residentes locales. 


\section{ESCENARIO POLÍTICO}

En lo que al escenario político respecta, estos fenómenos ocurren en un contexto marcado por la inestabilidad e incluso, en algunos casos, la agitación política. Esta situación tiene múltiples aristas, y una de ellas es la crisis de desconfianza hacia los gobiernos. Al respecto, la OECD (2019) en su informe registra que cerca del $77 \%$ de los latinoamericanos no creen en la honestidad de los procesos electorales, un $85 \%$ piensa que la corrupción es un fenómeno generalizado y alrededor del $66 \%$ duda del sistema judicial; estos porcentajes son los más altos con respecto a décadas anteriores. La pérdida de confianza en las instituciones democráticas aumentará exponencialmente si la ciudadanía no percibe desde los gobiernos respuestas adecuadas ante los desastres originados por la pandemia. Muestra de esto es que en muchos lugares la desprotección de los sectores más pobres y sus dificultades para contar con los bienes básicos de subsistencia han derivado en protestas y estallidos sociales de variable gravedad según las localidades.

A lo antes dicho, agreguemos que los Estados se vieron en la necesidad de avanzar sobre ciertas libertades de los ciudadanos para intentar contener los contagios. Muchos consideraron como la medida más efectiva evitar los contactos personales. En este caso, los gobiernos han implementado el aislamiento obligatorio, que restringe el derecho de circulación. En segundo lugar, muchas decisiones fueron impuestas por decreto porque la apremiante situación requería de una velocidad en la ejecución de políticas que no permite el debate legislativo ni el proceso habitual de sanción de leyes. En relación con esto, veamos la diferencia con tiempos anteriores a la pandemia cuando, por ejemplo, en Argenti- na, fueron tan discutidos los decretos de necesidad y urgencia incorporados en la última reforma constitucional de 1994. También, la postergación de actos eleccionarios es otra restricción de los derechos políticos. En diez países de la región, se aplazaron elecciones para llevarlas adelante, a la segunda mitad del año 2020. La mayoría eran sufragios subnacionales, aunque también cuenta aquí el esperado plebiscito en Chile y las elecciones nacionales en Bolivia y República Dominicana, entre otras.

Otra medida muy discutida fue la implementación de aplicaciones móviles para localizar a los ciudadanos. Los datos recopilados por estas tienen la finalidad de armar un árbol de contactos del enfermo, y así poder informarles y aislarlos, si fuera el caso, para evitar la propagación de la enfermedad. Además, se utiliza para identificar las zonas geográficas más complicadas por la epidemia. Estas herramientas han suscitado fuertes discusiones e, incluso, recursos ante la justicia, porque muchas personas las consideran como invasión a la privacidad y dudan del uso que se hará de los datos que estas aplicaciones recaban. En Argentina, por mencionar un ejemplo, el gobierno provincial jujeño se vio obligado a dejar de utilizar la aplicación SIMMOV, luego de la decisión de un juzgado en este sentido, a pesar de estar enmarcada en la ley nacional de protección de datos personales. Por último, citaremos la prohibición de protestas o manifestaciones públicas debido al confinamiento obligatorio.

Estas y otras medidas en la misma dirección solo son sostenibles dentro del Estado de Derecho si no se prolongan en el tiempo. Pero, al momento, en el ojo de la tormenta del covid-19, tampoco se puede definir cuánto es el tiempo necesario para frenar las consecuencias fatales del virus. 


\section{CONTEXTO INTERNACIONAL}

En cuanto el contexto internacional de los Estados, se observa que la crisis geopolítica ya iniciada en el 2008 tiene en el 2020 una "previsible profundización de la disputa geopolítica sobre América Latina y el Caribe entre los poderes globales establecidos y emergentes" (CLACSO, 2020). En este sentido, es imprescindible para América Latina tomar como una oportunidad la crisis de la pandemia y rever sus relaciones con las potencias mundiales. Es interesante observar cómo China ha abordado la pandemia con más coherencia y organización que Estados Unidos, o muchos de los países de Europa. Antes de la crisis originada por el covid-19, nuestra región había comenzado a establecer relaciones comerciales con Asia, cada vez más profundas. Este es el contexto en el que se amplían, quizás, las posibilidades de acentuar las relaciones con otros centros (como China, por ejemplo), en lugar de mirar a Estados Unidos o Europa como tanto tiempo lo ha hecho Latinoamérica. La globalización implica también esto: no dejar de conectarse con Estados Unidos o Europa, sino profundizar las relaciones con Asia, particularmente con China.

Desde el inicio de la pandemia, en Latinoamérica se hace cada vez más clara la necesidad de que los gobiernos planifiquen de forma consistente, coherente y adecuada a la coyuntura, con miras al largo plazo. Hoy, necesariamente, las medidas tomadas por los actores de decisión se van diseñando e implementado sobre la base de procesos de "prueba y error". Asimismo, se repite el problema de las contradicciones que surgen entre autoridades locales y gobiernos nacionales en cuanto a la toma de decisiones o implementación de políticas. Esta misma descoordinación se observa entre países al interior de los bloques de integración regional a los que pertenecen.

\section{LA GOBERNANZA LATINOAMERICANA EN CONTEXTO DE LA PANDEMIA DE COVID-19}

Luego de este recorrido por las áreas económica, social y política afectadas por la pandemia, volvamos a la definición de gobernanza propuesta, que nos es útil para analizar el escenario actual.

En primer lugar, como adelantamos párrafos atrás, con el término "gobernanza" hacemos referencia a las relaciones políticas entre los actores que intervienen en los procesos de decisión, ejecución y evaluación en asuntos de interés público. Esta parte del Estado se ve sumamente comprometida debido a la pandemia. Actualmente, se ha acentuado una tendencia que existía antes de la aparición del covid-19 que da cuenta de administraciones públicas descoordinadas que duplican esfuerzos y dejan necesidades sin cubrir mientras que otras sobreatendidas. En la región, muchas de las dificultades de los gobiernos para dar respuesta a la crisis provienen de la falta de acuerdos y cooperación entre gobiernos nacionales, provinciales y locales, o entre los representantes del oficialismo y la oposición (ya que no todo se pudo llevar adelante por decreto). Esta situación pandémica presiona a los gobernantes a poner entre paréntesis sus diferencias y lograr acciones coordinadas y eficaces. En los meses que van desde marzo a julio de 2020, ya podemos contar con muchas experiencias en América Latina en las que se ha podido comenzar a trabajar organizadamente. Por ello, se vislumbra una oportunidad de cambiar el rumbo de la política en nuestra región.

En este sentido, tenemos una visión optimista de la situación. Toda crisis es una posibilidad de crecimiento y oportunidad. Como contrapartida de lo antes expuesto, en muchos casos se vieron acuerdos y definiciones que se llevaron adelante entre partidos políticos o ni-

Omnia. Derecho y sociedad, núm. 3, 2020: 101-108 e-ISSN 2618-4699 
veles de gobierno que en otros momentos hubieran sido impensables. La pandemia puede ser el puntapié inicial para que actores diversos puedan ver que aunar esfuerzos, en pro de la ciudadanía, es ganancia para todos.

La pandemia hace patente la necesidad de avanzar hacia instituciones eficaces, abiertas e innovadoras para favorecer el desarrollo en la zona. Quizás, este sea el momento de que (a la fuerza) comiencen a surgir iniciativas de colaboración entre los actores que deciden (y se desarrollen las ya existentes).

Otro elemento de la conceptualización de gobernanza es el "juego de poder, en el cual competencia y cooperación coexisten como reglas posibles" (Whittingham Munévar, 2010, p. 221). Aquí, queremos detenernos una idea cada vez más difundida que sostiene que la globalización no ha funcionado como se esperaba y que es necesario reformarla profundamente. La fragilidad del sistema mundial se ha hecho mucho más evidente desde la crisis del 2008. Y esta situación ha sido agravada por las desigualdades entre los países y entre los grupos sociales. Todos los ciudadanos y gobiernos del mundo se encuentran inmersos en el contexto de la pandemia al mismo tiempo y esto podría servir para que los Estados se planteen seriamente la necesidad de reformular esas relaciones asimétricas y desiguales entre países y grupos sociales.

Por último, nos detengamos en el siguiente aspecto de la definición de gobernanza: "la forma e interacción entre los diversos actores refleja la calidad del sistema y afecta a cada uno de sus componentes; así como al sistema como totalidad" (Whittingham Munévar, 2010, p. 222). Sin duda, todo lo dicho en este trabajo muestra cómo la pandemia, en cuanto a la calidad del sistema, se ha mostrado como "una crisis dentro de otra crisis", que afecta tanto a los Estados como a los ciudadanos, al sistema político y a sus actores individuales. Es en este punto donde los actores locales tienen un papel mucho más relevante que en otros tiempos. Los gobiernos locales son protagonistas fundamentales de la gobernanza, pues es en los ámbitos más cercanos al ciudadano donde pueden abrirse espacios de participación e implementar acciones con más celeridad.

\section{CONCLUSIÓN}

A modo de conclusión, podríamos decir que el escenario tan desalentador que se presenta hoy ante los ojos de muchos latinoamericanos y de sus dirigentes debe ser visto como una oportunidad de cambiar el rumbo de las políticas públicas, de conducirnos hacia gobiernos más transparentes, innovadores y eficaces, de repensar las relaciones exteriores de competencia y cooperación. Probablemente, nunca antes atravesamos una situación donde todos podemos ser parte del problema y todos, también, parte de la solución.

\section{REFERENCIAS BIBLIOGRÁFICAS}

Beltramin, J. (2016). En torno al sentido de gobernabilidad y gobernanza: delimitación y alcances. Daimon. Revista Internacional de Filosofía, 67, pp. 149-162.

CLACSO. (2020). CovID-19: Catalizador de la crisis mundial y el nuevo papel de China. Recuperado de https://www.clacso.org/COVID19-catalizador-de-la-crisis-mundial-y-elnuevo-papel-de-china/

OECD et al. (2019). Perspectivas económicas de América Latina2019: Desarrollo en transición. Recuperado de https://www.oecdilibrary.org/docserver/g2g9ff1a-es.pdf?exp ires $=1599493060 \& i d=i d \& a c c n a m e=$ guest \&checksum =311C05EF4C55B57F8162DD6 D6CBB524C 
Organización Internacional del Trabajo. (2020). EI COVID-19 y el mundo del trabajo: Repercusiones y respuestas. Recuperado de https:// www.ilo.org/wcmsp5/groups/public/--dgreports/---dcomm/documents/briefingnote/wcms_739158.pdf

Organización Panamericana de la Salud. (2019). Indicadores básicos 2019: Tendencias de la salud en las Américas. Recuperado de https://iris.paho.org/bitstream/handle/10665.2/51543/9789275321287_spa. pdf? sequence $=7$ \&isAllowed $=y$

Robertson, R. (2003). Glocalización: tiempoespacio y homogeneidad-heterogeneidad. En Monedero (Coord.). Cansancio del Leviatán: problemas políticos de la mundialización, pp. 261-284. España: Trotta.
Sanahuja, J. A. (2020). covid-19: riesgo, pandemia y crisis de gobernanza global. En Mesa (Coord.) Riesgos globales y multilateralismo: el impacto de la COVID-19 Anuario (2019-2020). Recuperado de https://ceipaz. org/wp-content/uploads/2020/05/0.2020ANUARIO-COMPLETO.pdf

Wallace, A. (23 de marzo de 2020). Coronavirus: qué capacidad tienen realmente los países de América Latina para hacer frente a la epidemia de covid-19. BBC News Mundo. Recuperado de https://www.bbc.com/mundo/noticias-america-latina-51916767

Whittingham Munévar, M. V. (2010). ¿Qué es la gobernanza y para qué sirve? Revista Análisis Internacional, 2, pp. 219-236. 
